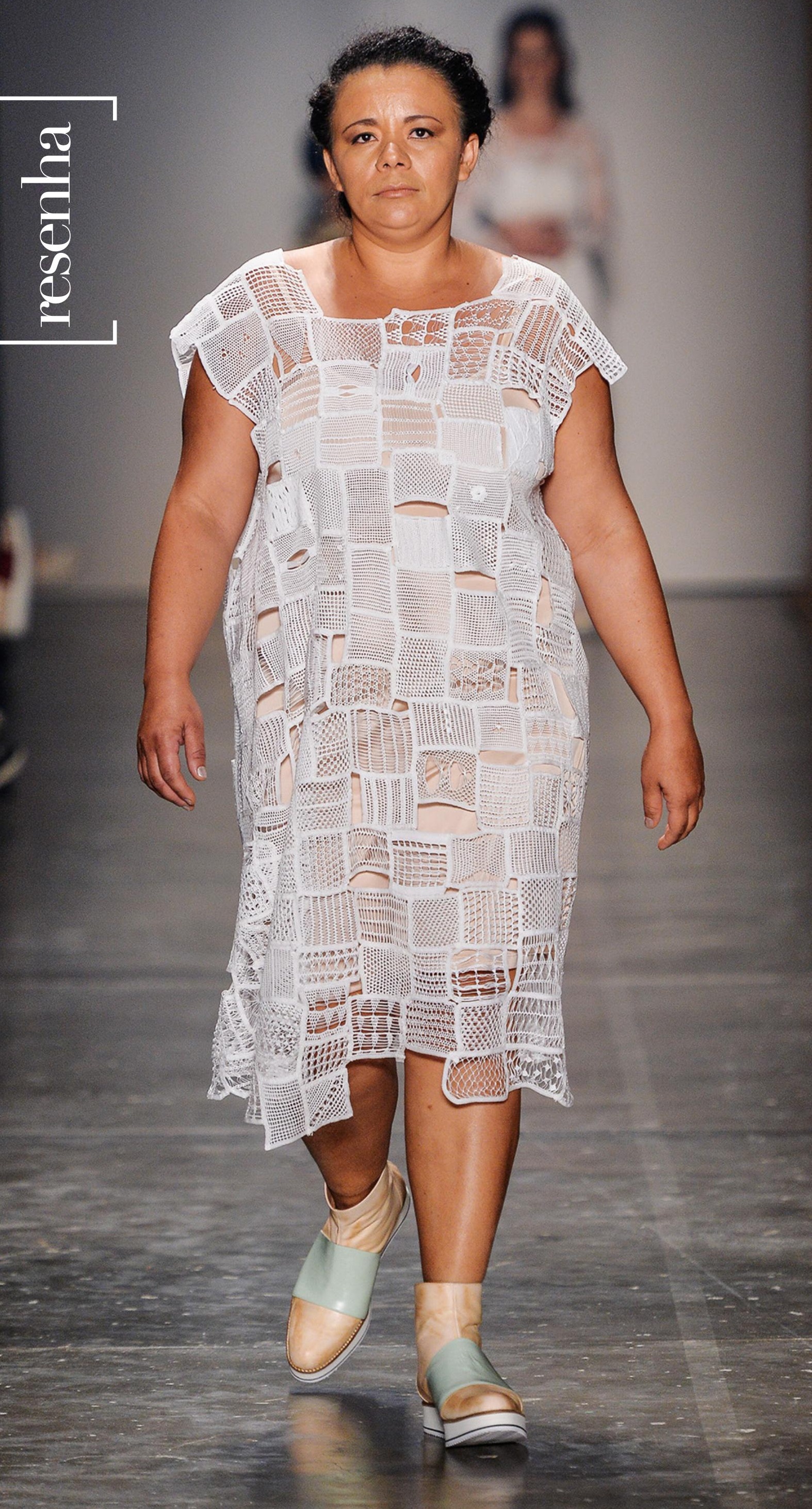


resenha ] vOLUME 10 | NÚMERO 21 | MAIO 2017

\title{
Precisamos falar sobre educação em moda
}

\author{
Resenha de CHRISTO, \\ Deborah Chagas. Estrutura \\ e funcionamento do campo \\ de produção de objetos do \\ vestuário no Brasil. São Paulo: \\ Estação das Letras e Cores, \\ 2016, 170 p. (1 $1^{a}$ edição).
}


Estrutura e funcionamento do campo de produção de objetos do vestuário no Brasil, de Deborah Chagas Christo, foi publicado em 2016 contribuindo para uma área de estudos ainda pouco explorada no país, que é a da educação em Design de Moda. Somando os tecnológicos e bacharelados, contamos atualmente no país com 224 cursos superiores em Design de Moda ${ }^{2}$ e afins, sem que essa oferta seja acompanhada por estudos sobre a educação em moda. Nesse sentido, a presente obra diminui essa lacuna e abre caminhos para pensar as perspectivas da formação e atuação neste campo no Brasil.

Decorrente de tese acadêmica defendida em 2013 no Programa de Pós-graduação em Design da Pontifícia Universidade Católica do Rio de Janeiro e, portanto, resultante de investigação que se desenvolveu pelo menos desde 2009/2010, a questão colocada por Deborah Christo àquela ocasião encontrava-se no momento de seu debate mais acalorado. A pergunta central que mobilizava os pesquisadores e educadores em moda - se o design de moda deveria ou não adequar-se às Diretrizes Curriculares Nacionais (DCN) do Design -, promoveu disputas nas instituições, cartas ao Ministério da Educação (MEC), polarizou o corpo docente das universidades, enfim, incentivou o debate e a reflexão tão necessários à educação em moda e aos rumos desse mercado.

Muitas abordagens poderiam ter sido feitas a partir dessa questão, as quais provavelmente teriam gerado teses de doutorado. Deborah Christo optou por entender quais são as motivações ou concepções mais profundas que sustentam 0 posicionamento daqueles que, oriundos do campo da moda - ou dos cursos de estilismo -, creem que submetê-los à área do design é limitador; e daqueles que, por outro lado, habitando tradicionalmente o campo do design, entendem que a moda, assim como vem sendo tratada, não deve fazer parte dele.

Para desenvolver seu argumento, a autora apropriou-se majoritariamente dos conceitos desenvolvidos por Pierre Bourdieu² e Gilles Lipovetskyª além de trazer inúmeros exemplos que demonstram como na prática essas fronteiras têm se dissipado e, entrelaçando-os ao processo histórico do desenvolvimento do campo educacional e profissional da moda no Brasil (ainda que as questões da prática profissional tenham sido abordadas em menor profundidade e extensão, limitando-se a alguns exemplos), descortina para o leitor aquilo que não havia sido dito abertamente nos debates. Esse é um dos pontos fortes e singulares que caracteriza essa pesquisa, pois a partir dos discursos proferidos a autora explorou as omissões, o não dito.

Os argumentos trazidos à tona para sustentar o descontentamento observado são suficientemente sólidos para explicar a razão pela qual a transição dos cursos de estilismo a cursos de design de moda "pode ser entendida como prejudicial em relação ao 'estilista'", pois parte das pessoas vinculadas ao ensino da moda entendeu que isso poderia "limitar e restringir a sua (do estilista) capacidade de criação e expressão" (p. 23). Ao mesmo tempo o texto especula que para o designer se trataria de incorporar a participação no campo do design de alguém fútil e pouco racional, o que foi justificado pela autora como uma herança da visão funcionalista do ensino do design no Brasil.

Embora a relação faça sentido, sobretudo considerando que a base teórica propõe a inevitabilidade da disputa no campo, pela leitura da obra se entenderia que os designers estariam igualmente insatisfeitos, opinião da qual discordo ao menos parcialmente. Não se pode esquecer que esse processo acabou por estabelecer uma hierarquia na área da educação em moda/design a partir da qual pesquisadores e docentes filiados por formação ao campo do design levaram certa vantagem, pois aparentemente o MEC insinuava que a moda deveria "submeter-se" ao design, reconhecendo nele os atributos científicos que pareciam faltar aos cursos de moda no pais. Nesse sentido, embora a pesquisa enfatize bem mais 0 
ponto de vista daqueles que provêm do campo da moda, o que pôde ser vivenciado desde a perspectiva dos "tradicionais" designers é que esse processo não deveria se limitar a um acolhimento - o design deveria passar a tratar de assuntos filiados à moda a partir de então -, mas sim à imposição das tradições metodológicas deste campo destituindo de valor parte da trajetória e da relevância do setor de moda no país. Por essa razão, sintetiza a autora, "não parece ser um processo que esteja sendo facilmente compreendido e assimilado" (p. 22).

0 entendimento do confronto estudado por Deborah Christo será facilitado se houver por parte do leitor conhecimento da causa, de modo que, pelo menos na forma de livro, consideraria relevante adicionar um prólogo no qual se apontassem os mecanismos de aferição do MEC, o processo de autoproteção desencadeado nas instituições e, finalmente, os temores envolvidos nessa transição, provavelmente ponto mais importante do debate.

No que diz respeito aos meios de verificar se os antigos cursos de estilismo que, diga-se de passagem, já se nomeavam como cursos de Design de Moda, passariam a ser aferidos pelo Enade e pelos processos de reconhecimento como qualquer curso de design. Para não ver-se obrigado a atender as "exigências" do MEC, originou-se um documento assinado por diferentes instituições de ensino que visou defender a moda como "um campo específico do saber" pois o designer de moda "não faz somente design" ${ }^{5}$ na opinião daqueles. Se, por fim, não houvesse como resistir, na prática a transição significaria alterar as bases nas quais a formação da profissão se sustenta, o que exigiria transformar currículos, renovar corpo docente, investigar novas bibliografias etc., além de rever os valores associados a esse campo profissional. 0 último ponto foi o que recebeu a atenção da autora, tratado ampla e profundamente pela pesquisa.

Essa questão está desenvolvida em três capítulos centrais. Primeiramente, o leitor é introduzido aos conceitos e definições mais elementares à cultura de moda utilizando a base teórica que servirá à análise das hipóteses, em seguida a autora mostra como tais conceitos e definições se constituiram no Brasil e, finalmente, discute-se como os valores resultantes dessa combinação conformaram a estrutura interna do campo da moda no Brasil. Nessas três etapas Deborah Christo não enfatiza as questões tangiveis da moda, como formas, materiais ou processos eventualmente distinguiveis quando oriundos do estilista ou do designer; bem mais que isso, trata de como a moda se manifesta, se constitui e se estrutura desde uma perspectiva simbólica, o que permite analisar os efeitos desse processo de transição pelo qual o ensino de moda brasileiro ainda vem passando.

Uma escrita densa apresenta as manifestações da moda a partir das contribuições de Pierre Bourdieu e Gilles Lipovetsky. Assumindo o formato de uma revisão bibliográfica, a autora vai mostrando como a moda se estabelece como um fenômeno social com caracteristicas hoje em dia tão reconhecíveis, sendo a principal delas, talvez, o apreço pela novidade. Nesse capítulo apresenta-se a visão de Deborah Christo ao esclarecer detalhadamente a origem do confronto entre os profissionais do campo, baseada em uma disputa por distinção e reconhecimento que é muito acirrada: por um lado, emerge a figura do profissional costureiro aderente à alta-costura e que representaria a oportunidade de manifestar o espírito criador sobretudo erudito, e, por outro - bem menos enfatizado na tese - , a pesquisa descreve aqueles que se assemelhariam aos designers por se dedicarem à produção em larga escala e cederem ao gosto da massa, o que é sintetizado na ideia do atendimento aos desejos do mercado.

Para Deborah Christo, os valores associados a cada um desses perfis não se limitam à sua postura individual. Ao contrário, estão espelhados na "criação, desenvolvimento, produção, consagração, difusão, distribuição e recepção dos objetos do vestuário" (p. 51) que se instalou no espaço social, no qual, em teoria, o estilista 
seria mais valorizado que o designer. Por esse caminho chega-se àquilo que, acredita a autora, passaria a ser uma das razões pelas quais se deu a resistência por parte dos cursos de design de moda às DCN do design: os criadores consagrados entenderiam como perda de prestígio atuarem e assumirem-se como designers principalmente por estarem submetidos ao mercado.

Esse ponto exige que a leitura da obra acompanhe reflexão simultânea com nosso processo histórico e com as perspectivas mercadológicas e educacionais da moda no Brasil, não devendo ser interpretada isoladamente a fim de não incorrer no risco de não entender o porquê de não manter as duas formações desvinculadas já que cada uma desempenharia seu próprio papel na sociedade.

É necessário tomar como premissa que as orientações do MEC, ao menos teoricamente, se enquadram em uma visão macro do país por perseguir seu desenvolvimento humano, econômico e social, onde o ensino de moda é considerado uma das áreas estratégicas a ser potencializada. Analisando o contexto contemporâneo da sociedade brasileira, as demandas impostas pelo MEC buscam o alinhamento da oferta formativa à realidade social e, dessa forma, podemos interpretar tais diretrizes como uma forma de corrigir o traçado dos objetivos da formação inicialmente propostos, quando do início do ensino do design de moda no Brasil.

As distorções dos objetivos educacionais em moda, os quais foram desenhados pelas necessidades industriais, desprendem-se das entrelinhas do capítulo dedicado à constituição do campo da moda no Brasil. Como bem pontuou Deborah Christo, apesar das condições brasileiras, a cultura de moda aqui se estabeleceu reproduzindo o mesmo enfrentamento no campo que havia na Europa, embora em condições muito distintas.

Há 50 anos, além da produção em larga escala de roupas consideradas de menor qualidade, havia também no Brasil "ateliês" e "casas" que também criavam, mas que muito se dedicavam a reproduzir (copiar) artesanalmente roupas estrangeiras e, ainda assim, a "assinatura ( $d a$ casa ou ateliê) atribuía valor diferenciado e superior aos objetos desenvolvidos, entendidos como únicos, exclusivos e originais" (p. 60). 0 valor da criação como inovação ainda não era um conceito arraigado e a cópia bem-feita, para assemelhar-se ao estrangeiro, era muito apreciada. Essa visão modificou-se mais tarde, ao redor da década de 19706, sem que isso signifique que o procedimento da cópia se extinguiu.

A autora não se dedicou a explicar como a mudança no formato dos negócios impactou o desenvolvimento de produtos, entretanto, estima-se que tal modelo determinou os valores que se instalariam na educação em moda no Brasil7, reverberando no ensino superior uma década mais tarde. Assim, a leitura desse capítulo deve tomar como pressuposto que o crescimento da moda no Brasil descrita por Deborah Christo fortaleceu a indústria que, por sua vez, estimulou a valorização de um perfil profissional que interessava a ela, sem que, necessariamente, esse profissional contribuísse de modo mais intenso com toda a sociedade. Essa "nova categoria de produtores (...), apesar de estar vinculada à produção industrial em larga escala, é legitimada por uma capacidade autoral autônoma" (p.63) à ocasião, ainda que orientada pelas informações estrangeiras. Isso viria a explicar, por exemplo, o desenho de metodologias e disciplinas que utilizavam "tendências" ou "referências" como disparador dos processos criativos.

Aquilo que foi visto como importante, útil, necessário e pertinente na década de 1980, quando os objetivos formativos para o ensino de moda no Brasil que hoje associamos ao estilismo foram colocados, nos permite acessar a reflexão mais instigante proposta pela autora no que diz respeito à passagem do ser estilista para ser designer. Enfatizando as polarizações entre o comercial/conceitual, mercadoria/cultura, erudição/massa etc., Deborah Christo nos estimula a repensar 
sua coerência no Brasil de hoje pelo menos com relação à absorção, pela sociedade (empregos, empreendedorismo, pesquisa acadêmica ou tecnológica, atuação nas áreas correlatas etc.), de profissionais com dita expectativa de valorização.

A pesquisa não se dedicou a demonstrar qual modelo de formação implantado nos anos 1980 visava atender tanto ao desafio de produzir roupas em escala industrial (p.71) quanto ao de conservar a aura artística associada à criação (p.77) no desenvolvimento de produtos diferenciados e com identidade própria (p.71), mas pode-se deduzir que as transformações curriculares ao longo de trinta anos não tenham alterado a percepção do que seria o estilista: um profissional capacitado para a criação autônoma que ocuparia uma posição privilegiada no campo.

Se a formação em design dos anos 1960 aos anos 1990 pouco tangenciava a área de moda e vice-versa, as mudanças pelas quais o país passou desde então apontam para perspectivas de atuação no campo da moda e do design muito diferentes daquelas que estimularam sua implantação. Nesse sentido, trazendo elementos de análise tão bem tratados por Deborah Christo, conclui-se que ao aceitar que o campo da criação em moda se comporte como estabelecem as DCN do design, a moda passará a ocupar um lugar "no campo" diferente daquele imaginado inicialmente, lugar esse que na visão mais arraigada não possui posição tão distintiva quanto até então o era.

É nesse ponto que creio que a passagem de tese a livro mereceria uma ampliação, aproximando ao leitor pouco iniciado as questões por trás da hipótese colocada e, também, o aprimoramento da diagramação, tornando-a mais atrativa e fluida, o que contribuiria para suavizar o caráter de tese acadêmica e de sua rigidez, apesar da coleção Teses e Tramas dedicar-se a esse fim, ou seja, justamente proporcionar visibilidade às pesquisas acadêmicas de excelência, conforme está descrito no posfácio. Além da carência de um prólogo, como inicialmente colocado, um diálogo com as questões práticas que emergem no cotidiano educacional e produtivo em moda, ampliariam significativamente a reverberação do texto e, não só este, mas de todas as teses publicadas nessa área, tornando-se mais acessiveis aos estudantes em diferentes níveis.

Deborah Christo traça um interessante caminho de reflexão sobre as razões pelas quais o caráter da formação em moda impacta toda a sociedade. A defesa de um modelo educacional nem sempre é a defesa da área de atuação, de modo que as mais de 30 mil vagas autorizadas pelo MEC anualmente ${ }^{8}$ devem encontrar eco em todo o país, atendendo às necessidades da população, bem como do mercado internacional, sem que isso signifique submissão aos desejos da massa. Considero essa pesquisa um incentivo à discussão sobre os "valores e critérios" que atravessam o campo da moda a fim de que possamos considerar mais formas de atuação e encontrar mais destinos para a nossa criação. 


\section{NOTAS}

1. A pesquisa Estudo comparativo sobre a formação para a prática do projeto em Design de Moda é realizada com o apoio da Universidade Anhembi Morumbi. Está sendo mapeada a oferta do ensino superior em moda no Brasil, considerando cursos oferecidos pelas instituições públicas e privadas em todo o território nacional, somente presenciais e nas modalidades bacharelado e tecnológico. Foram tomados como cursos dentro da área de design de moda cursos como produção do vestuário e outras nomenclaturas ainda vigentes. A apuração dos dados mencionados se deu em outubro/2016 e foi realizado pela estudante Laura Paiva sob minha orientação.

${ }^{2}$ A principal obra de Pierre Bourdieu utilizada como fundamentação foi 0 costureiro e sua grife: contribuição para uma teoria da magia (1974) escrita com Yvette Delsaut.

${ }^{3}$ Segundo Deborah Christo, a seleção de O império do efêmero (1989) se deu, entre outras razões, porque é uma obra amplamente utilizada nos cursos de moda no Brasil e, portanto, influenciando-os. Além disso, destaca a autora, esta obra opõe-se à proposta de Pierre Bourdieu, criando um interessante contraponto.

${ }^{4} 0$ Exame Nacional de Desempenho do Estudante (Enade) é obrigatório aos estudantes concluintes do ensino superior, quando seu ano de conclusão se encontre em periodo avaliativo. Em geral é uma prova de múltipla escolha com questões dissertativas que tem uma parte geral e outra específica. Na parte específica, são colocadas questões diretamente relacionadas com as Diretrizes Curriculares Nacionais para o curso que está sendo avaliado. A nota média do Enade obtida pelos alunos de um dado curso tem impacto na avaliação desse curso, pois é uma nota pública. Maus resultados no Enade submetem as instituições a outros procedimentos avaliativos por parte do MEC.

${ }^{5}$ Tratou-se de um documento redigido e encaminhado ao MEC em 2011 com a assinatura de diferentes instituições de ensino para solicitar que a moda fosse considerada uma área específica do saber para não necessariamente submeter-se às diretrizes do design.

${ }^{6}$ É provável que já tivesse começado pelo menos uns vinte ou vinte e cinco anos antes, em decorrência da superprodução gerada pela Segunda Guerra.

'Consultar Branislav Kontic (2007). 0 autor demonstra como a indústria desenhou o perfil profissional ideal para seu modelo de negócio, apontando as implicações da ausência da participação do governo naquele momento.

${ }^{8}$ Segundo a pesquisa realizada pela Universidade Anhembi Morumbi já mencionada. A autorização para a oferta de vagas não significa necessariamente a entrada anual de todos esses alunos na universidade.

\section{REFERÊNCIAS}

FASM. Moda como um campo específico do saber. Demanda das Escolas de São Paulo. São Paulo: Coord. Faculdade Santa Marcelina, FASM, 2011 (mimeo).

KONTIC, B. Inovação e redes sociais: a indústria da moda em São Paulo. São Paulo: FFLCH, 2007. 